\title{
Práticas de escrita em contexto de Concurso Vestibular: a atuação de candidatos na prova de Redação ${ }^{1}$ \\ Writing practices in University admission test: candidates' performance in essay exam
}

\section{Adriana Beloti}

\section{Cleber da Silva Luz}

Universidade Estadual do Paraná - UNESPAR - Campo Mourão - Paraná - Brasil

\begin{abstract}
Resumo: Este artigo analisa a atuação de candidatos em práticas de escrita na situação de Concurso Vestibular - CV. Pautados em trabalhos de Fiad e Mayrink-Sabinson (1991) e Menegassi (2016) acerca da escrita como trabalho; Menegassi (2011) e CostaHübes (2012) sobre condições de produção para a escrita de textos em situação de Concurso Vestibular; em Bakhtin/Volochinov (1992) e Bakhtin (2003) a respeito da perspectiva discursiva de linguagem e a concepção de gêneros discursivos, tomamos como objeto de análise 126 produções textuais, realizadas por candidatos ao Curso de Letras/Campus de Campo Mourão, do Concurso Vestibular da Universidade Estadual do Paraná - Unespar, na prova de Redação das edições de 2016/2016, 2016/2017, 2017/2018, partindo de critérios estabelecidos pelos pesquisadores, sem relação com a avaliação feita pela banca examinadora do CV. Foram observados dois aspectos: a) organização composicional; b) conteúdo temático e particularidades que estejam ligadas aos dois elementos. As análises revelaram que, referente ao tópico (a) os candidatos demonstraram desconhecer a composição dos gêneros discursivos solicitados, fator que acarreta na produção de textos sem marcas típicas ou, ainda, de gêneros diferentes dos solicitados. Quanto ao ponto (b), os candidatos demonstraram estar mais próximos do atendimento, uma vez que, na maioria das produções, atendem ou atendem parcialmente ao proposto pelo encaminhamento de produção textual. Os resultados indicam a incompreensão da prática discursiva de trabalho com gêneros discursivos, implicando em textos que não atendem à situação enunciativa.
\end{abstract}

Palavras-chave: Práticas de escrita. Prova de Redação. Concurso Vestibular.

Abstract: This article reviews the writing performance of candidates applying for a University admission test.Based on the works of Fiad and Mayrink-Sabinson (1991) and Menegassi (2016) about writing as work; Meegassi (2011) and Costa-Hübes (2012) about text production conditions in admission tests; established on Bakhtin/Volochinov (1992) and Bakhtin (2003) about the discursive perspective of language and the discursive genres. In order to do that, we took as an object of analysis 126 textual productions, made by candidates applying to the Languages course/Campo Mourão campus of Paraná State University - UNESPAR, during the essay exams from the years of 2016/2016, 2016/2017, 2017/2018. The texts' analysis were based on criteria established by the researchers, without any relation to the examining board's evaluation. Two aspects were observed: a) structural organization and (b) thematic content, as well as particularities related to these two elements. The analysis of the topic (a) revealed that candidates appeared to not know the composition of the requested discursive genres, which is a factor that leads to textual productions with no typical marks or even with genres that differ from the requested. As for topic (b), candidates seemed to be closer to fulfilling that demand, since in most textual productions they answered or partially answered the essays' requests. The results can unveil reminiscent writing practices from Basic School, which has not internalized discursive practice with discursive genres yet. The results appoint misunderstanding of the discursive practice of work with discursive genres, implying in texts that don't meet the criteria of the enunciative situation.

Keywords: Writing practices. Essay exam. University entrance exam.

\footnotetext{
1 As análises apresentadas neste artigo são oriundas dos resultados da pesquisa "Provas de Redação do Concurso Vestibular da UNESPAR: condições de produção e atuação de candidatos", desenvolvida com apoio financeiro da Fundação Araucária do Paraná.
} 


\section{Introdução}

Considerando os processos de escrita em situação de Concurso Vestibular e as possíveis relações que podem ser estabelecidas com as práticas de escrita nas escolas de Educação Básica, este trabalho busca apresentar uma análise acerca da atuação de candidatos que realizaram o Concurso Vestibular da Universidade Estadual do Paraná Unespar, nas edições de 2016/2016, 2016/2017 e 2017/2018, tencionando identificar como se dá o atendimento às propostas de produção textual de tais edições do Concurso².

A partir das análises, identificamos como, possivelmente, as atuações dos candidatos e recorrências que os textos revelam podem estar atreladas às experiências do processo de ensino na Educação Básica, uma vez que, em certa medida, estes candidatos ao Concurso Vestibular foram, anteriormente, estudantes do sistema de ensino básico/regular.

Para tanto, partimos da concepção de escrita como trabalho, com base nos pressupostos de Fiad e Mayrink-Sabinson (1991) e Menegassi (2016), bem como das propostas do Círculo de Bakhtin no que tange à perspectiva discursiva de linguagem (BAKHTIN/VOLOCHINOV, 1992), uma vez que os documentos oficiais, como os Parâmetros Curriculares Nacionais - PCN (BRASIL, 1998), e as principais teorias sobre o ensino e aprendizagem de Língua Portuguesa partem dessa compreensão de língua e de linguagem tomando-a como fundante. Pautamo-nos, ainda, nos trabalhos de Geraldi (1997), acerca da produção de textos nas escolas, considerando as condições de produção que orientam o processo de escrita, tratadas por Menegassi (2011) e Costa-Hübes (2012).

\footnotetext{
2 Este estudo considera trabalhos anteriores (LUZ; BELOTI, 2018; 2018a) nos quais são analisados os encaminhamentos de produção textual quanto ao estabelecimento das condições de produção necessárias para a escrita de textos em determinadas situações enunciativas.
}

\section{A produção textual em situação de Concurso Vestibular}

A partir da proposta dos Parâmetros Curriculares Nacionais - PCN (BRASIL, 1998) de trabalho com os gêneros discursivos (BAKHTIN, 2003) nas disciplinas de Língua Portuguesa, ancorado numa perspectiva discursiva de linguagem, concebendo-a como uma prática social (BAKHTIN/VOLOCHINOV, 1992), a produção textual, nas situações de ensino e aprendizagem de línguas, considera a proposta de escrita como trabalho (FIAD; MAYRINK-SABINSON, 1991), a partir da qual o texto é produzido em etapas, considerando o momento de planejamento, execução, revisão e reescrita (MENEGASSI, 2016).

As organizações composicionais típicas de enunciados cumprem funções sociais e comunicativas em determinados contextos de interação verbal social, a partir das quais sujeitos interagem em situações diversas. A essas organizações atribuiu-se a denominação de gêneros do discurso. Esses, para Bakhtin (2003), são conceituados como "[...] tipos relativamente estáveis de enunciados [...]" (BAKHTIN, 2003, p. 262, grifos do autor), sendo por meio deles que os sujeitos organizam seus modos de dizer na sociedade. São relativamente estáveis, pois tendem a variar por serem flexíveis às finalidades do sujeito que utiliza a língua(gem) em diversas situações reais de enunciação.

Para o trabalho com a produção de textos pautado na proposta dos gêneros discursivos, ancorado nos preceitos do Círculo de Bakhtin, Menegassi (2011) afirma ser necessário que, para solicitar uma produção textual, seja disponibilizado um encaminhamento de produção, a partir do qual condições de produção sejam estabelecidas aos produtores do texto. Tais condições são a delimitação da finalidade de produção do texto, do interlocutor para o qual se escreve, a partir de qual gênero, com temática, circulação e suporte do texto definidos, estabelecendo um posicionamento social a partir do 
qual o sujeito produtor enuncia. Acerca das condições de produção, observamos que, além das mencionadas por Menegassi (2011), Costa-Hübes (2012) propõe que se estabeleçam estratégias para que o sujeito tenha melhores condições de produzir seu texto, sendo consideradas um elemento a mais na composição de comandos de produção textual.

A delimitação da finalidade, do interlocutor, do gênero textual ${ }^{3}$, da temática do texto, da circulação social, do suporte textual, do posicionamento do autor e das estratégias (MENEGASSI, 2011; COSTAHÜBES, 2012), atende ao que propõe Geraldi (1997), quando afirma ser necessário em toda situação de ensino e aprendizagem de línguas dar condições para que o produtor do texto tenha o que dizer, uma razão para tal fim, tenha para quem dizer, se constitua como sujeito que diz o que diz para seu interlocutor e, a partir disso, escolha as estratégias para realizar (GERALDI, 1997) seu "[...] livre projeto de discurso [...]" (BAKHTIN, 2003, p. 285).

Entre os elementos das condições de produção já mencionados anteriormente ressaltamos, ainda, a necessidade de discutir de modo mais sistemático o interlocutor (MENEGASSI, 2011), pois possui particularidades no processo de análise e compreensão de sua função na produção textual, sobretudo no que concerne à sua atuação na situação de Concurso Vestibular.

\section{O interlocutor no contexto da prova de redação do Concurso Vestibular}

Ao tratar do interlocutor, elemento essencial ao nos referirmos às situações de produção de textos em situação de Concurso Vestibular, Menegassi (2011) discute seus três tipos: real, virtual e superior.

No que concerne ao interlocutor real, Menegassi (2011) e Silva (2018) afirmam que diz respeito à pessoa que tem a presença física no

\footnotetext{
${ }^{3} \mathrm{O}$ uso do termo gênero textual segue as considerações de Menegassi (2017) ao afirmar que, em contexto de Concurso Vestibular, impedido o trabalho com as reais funções sociais dos gêneros solicitados, tendo como princípio um objetivo avaliativo, tratamos não de gêneros discursivos, mas sim, textuais.
}

momento de escrita do texto. Se refletirmos acerca da situação de ensino e aprendizagem de Língua Portuguesa, esse interlocutor é sempre o professor para o qual se destina a produção do estudante, pois, nesse contexto, o professor, além da pessoa física que está presente no momento de escrita, é a imagem a qual o estudante recorre para nortear o seu processo de escrita, ou seja, o estudante produz seu texto a partir da constituição que faz de seu interlocutor real que, neste caso, trata-se do professor.

Já na situação do Concurso Vestibular, ao retomarmos a ideia de que o interlocutor real será sempre a pessoa que está participando fisicamente do processo de escrita do texto, teremos, então, como interlocutor com tal característica, o aplicador da prova, que pode ser um técnico universitário, um estagiário ou um professor da universidade. Em contrapartida, ao discutir esse tipo de interlocutor, Beloti (2016) afirma que, embora a prova seja aplicada por um representante da instituição, é o professor quem tem a imagem constituída no momento de escrita pelo candidato, ou seja, o candidato recupera a imagem de um professor que fora, em situações de escrita anteriores, o interlocutor que orientou seu processo de escrita, direta ou indiretamente.

Sobre o virtual, Menegassi (2011) afirma que será sempre aquele marcado no comando de escrita ou inferido pela situação hipotética que é instaurada para o contexto de produção textual, para que se atribua ao texto produzido pelo candidato uma real situação ou o mais próximo dessa, considerando as funções que os textos cumprem socialmente nos contextos de interação verbal social, ou seja, nas escolas os estudantes produzirão textos que, embora tenham função avaliativa e o professor será o interlocutor de fato, ao marcar um interlocutor que atenda à expectativa de interlocução dessa produção em uma situação real, o estudante poderá ter consciência dessa prática ao produzir um gênero específico para um interlocutor definido ao interagir socialmente. 
Quanto ao superior, para o autor (2011), será sempre a instituição de ensino, pois estipula regras e determina critérios a serem atendidos pelos candidatos no momento de realização da Prova de Redação. Assim, é considerado que, em situação de ensino e aprendizagem, há sempre a escola como interlocutor superior dos estudantes e, em situação de Concurso Vestibular, a instituição de Ensino Superior.
A partir dessas reflexões, observamos os interlocutores real, virtual e superior, suas representações e suas especificidades na situação de Concurso Vestibular, exemplificando a partir do Encaminhamento de produção textual referente à edição de 2016/2017 disponibilizado aos candidatos para a Prova de Redação. Observamos o Quadro 1:

Quadro 1: Interlocutores e suas representações da Prova de Redação de 2016/2017

\begin{tabular}{|c|c|c|c|c|}
\hline $\begin{array}{l}\text { Encaminhamento de } \\
\text { produção 2016/2017 }\end{array}$ & \multicolumn{4}{|c|}{$\begin{array}{l}\text { "Você leu o texto A cegueira universal em um mundo tomado pelas imagens, veiculado } \\
\text { no site Observatório da Imprensa, revista semanal de crítica da mídia, editada pelo } \\
\text { jornalista Alberto Dines. A partir das informações e argumentos apresentados, você } \\
\text { decidiu escrever ao editor, posicionando-se quanto à ideia de que o excesso de } \\
\text { imagens não amplia a visão de mundo. } \\
\text { Como leitor dessa revista eletrônica, produza uma CARTA DO LEITOR, entre } 15 \text { e } 18 \\
\text { linhas, expondo, com argumentos, seu posicionamento em relação à temática." } \\
\text { (UNIVERSIDADE ESTADUAL DO PARANÁ, 2017). }\end{array}$} \\
\hline Interlocutor & $\begin{array}{l}\text { Conceito } \\
\text { teórico }\end{array}$ & Representação & $\begin{array}{c}\text { Conceito } \\
\text { prático }\end{array}$ & Representação \\
\hline Real & $\begin{array}{l}\text { Está fisicamente e } \\
\text { marca presença no } \\
\text { momento de } \\
\text { aplicação da prova e } \\
\text { processo de escrita } \\
\text { do texto }\end{array}$ & Aplicador da prova & $\begin{array}{l}\text { Trata-se de um real- } \\
\text { imaginado que o } \\
\text { candidato recupera a } \\
\text { imagem e o ativa no } \\
\text { momento de } \\
\text { realização da prova, } \\
\text { considerando outros } \\
\text { momentos em que } \\
\text { produziu textos }\end{array}$ & Professor \\
\hline Virtual & $\begin{array}{lr}\text { Tem sua imagem } \\
\text { constituída } \\
\text { recuperada pelo } \\
\text { candidato no ato de } \\
\text { escrever }\end{array}$ & $\begin{array}{l}\text { Editor da revista } \\
\text { Observatório da } \\
\text { imprensa }\end{array}$ & $\begin{array}{l}\text { É quem } \\
\text { conduzindo } \\
\text { escolhas que } \\
\text { candidato faz as } \\
\text { produzir seu texto, } \\
\text { pois é quem avaliará, } \\
\text { dando as respostas } \\
\text { quanto à aprovação } \\
\text { ou não na Prova de } \\
\text { Redação }\end{array}$ & Instituição \\
\hline Superior & $\begin{array}{lr}\text { Responsável } & \text { por } \\
\text { delimitar os padrões } \\
\text { e regras a } & \text { serem } \\
\text { seguidas } & \text { pelo } \\
\text { candidato } & \text { no } \\
\text { momento } & \text { de } \\
\text { produção do texto }\end{array}$ & Instituição & $\begin{array}{lr}\text { Responsável } & \text { por } \\
\text { delimitar os padrões e } \\
\text { regras a } & \text { serem } \\
\text { seguidas } & \text { pelo } \\
\text { candidato } & \text { no } \\
\text { momento de produção } \\
\text { do texto }\end{array}$ & Instituição \\
\hline
\end{tabular}

Fonte: Os pesquisadores. 
consideramos, aqui, o interlocutor na situação do CV em dois planos: o primeiro diz respeito ao conceito estabelecido, o qual denominamos conceito teórico; o segundo, se trata do conceito "real", aqui designado como conceito prático. O conceito teórico está sendo compreendido a partir do que as teorias propõem e considerando 0 que os Encaminhamentos de produção estabelecem, sem levar em consideração o contexto mais específico. Já o conceito prático está fundamentado no conceito teórico, mas considera a situação enunciativa do Concurso Vestibular.

Com base na análise do Encaminhamento de produção textual da edição de 2016/2017, podemos compreender que, os interlocutores real, virtual e superior têm diferentes representações se analisados a partir do conceito teórico e do conceito prático. Considerando a conceituação para cada um dos interlocutores apresentados anteriormente, observamos que, no plano teórico, a Prova de Redação de 2016/2017 tem como correspondente aos interlocutores real, virtual e superior, o Aplicador da prova, o Editor da revista Observatório da imprensa e a Instituição, respectivamente.

Tais representações atendem ao proposto pelo conceito teórico quando afirmam a correspondência para cada interlocutor como: para o real, a presença no momento de produção do texto, esse por sua vez, corresponde ao Aplicador da prova; para o virtual, o marcado pelo Encaminhamento ou inferido pela situação, nesse contexto, ao solicitar o gênero Carta do Leitor e marcar linguisticamente a finalidade de responder ao texto do Editor publicado na revista, esse interlocutor endereçado (o Editor da revista) assume posição de interlocutor virtual; para o superior, como o responsável por estipular critérios maiores de produção das provas, de modo que se atribui à Instituição a representação desse interlocutor.

Observando o Quadro 1, a partir da compreensão do conceito prático para cada interlocutor, pautados nas acepções atribuídas pelo conceito teórico e, neste caso, levando em consideração a situação em que ocorre o CV, compreendemos que a representação dos interlocutores correspondentes ao real e virtual na situação do Concurso Vestibular se dá de modo complexo. A partir disso, buscamos refletir acerca dessas constituições, considerando suas funções no processo de produção textual, uma vez que ambos têm forte impacto na produção dos textos, partindo do fato de que os candidatos tendem a produzir seus textos a partir de determinada imagem que se tem do interlocutor (BRITTO, 2006), pois, conforme afirma Faraco (2014), toda produção escrita diz respeito a uma prática situada entre determinada atividade social, na qual escrevemos sempre para alguém ler, ou seja, há sempre um interlocutor com o qual dialogamos.

O aplicador da prova, presente no momento da escrita, solicitando e encaminhando a produção da Prova de Redação ao candidato, está presente fisicamente no ato da escrita dos textos, de modo que pode ser considerado o interlocutor real do candidato, sob a ótica do conceito teórico. Acerca da imagem do aplicador da prova, Silva (2018) afirma que, ao assumir a posição de interlocutor real, representa a banca de avaliação da redação, uma vez que ela, de fato, é quem lerá e avaliará o texto do candidato, ou seja, a banca de avaliação é que constitui essa função de interlocutor do processo de escrita das redações do CV. Nesse sentido, observamos que, embora o aplicador esteja presente no momento da escrita do texto, esse não tem sua imagem atribuída como norteadora do processo de escrita dos candidatos, uma vez que participa dessa situação enunciativa como representação da banca da avaliação da prova.

Dessa forma, diante da asserção de conceito prático, compreendemos que o interlocutor real, nessa situação, refere-se à imagem do professor. Mesmo que ainda não conceituada pelas teorias que tratam do processo de escrita em situação de CV, tal imagem é bastante significativa ao refletirmos a respeito da situação de produção textual, que implica um status dialógico que lhe é intrínseco, sobretudo pelo fato de toda situação de produção de textos envolver uma relação de interação entre dois ou mais sujeitos, em um determinado contexto de interlocução 
(SOBRAL; GIACOMELLI, 2016). Sobre essas proposições, Sobral e Giacomelli (2016) asseveram que:

A interação entre dois interlocutores envolve a sociedade e a história, ou seja, suas posições sociais ao longo do tempo, suas diferentes posições sociais (pai-filho, professora-aluno, chefe-chefiado, pessoa de classe alta ou baixa, por exemplo) e suas relações sociais, não apenas entre si no momento da interação, mas ao longo da vida, com outras pessoas, em diversos ambientes (SOBRAL; GIACOMELLI, 2016, p. 1082).

A compreensão de que uma situação enunciativa que envolve dois ou mais interlocutores tem caráter dialógico e opera a partir da interação é o ponto de início de nossas reflexões, sobretudo pelo fato de entendermos que, em determinadas situações enunciativas, 0 contexto pode determinar interlocutores que não estarão presentes fisicamente, naquele momento, mas sim, presentes a partir de uma memória discursiva constituída ao longo do tempo e recuperada na situação de escrita.

Há, nesse sentido, além de um aqui e um agora, um tempo que é histórico e enraíza determinadas enunciações por meio de um tempo que, dotado de responsividades e contrapalavras, constitui um momento presente no e pelo discurso (SOBRAL; GIACOMELLI, 2016). A compreensão do nível de interação que considera o horizonte social amplo, proposto pelos autores (2016), possibilita-nos refletir acerca da imagem do professor e inferi-lo como o interlocutor real da prova de Redação no contexto do CV, pois, segundo os autores (2016, p. 1083), "A interação refere-se [...] a todas as situações em que pessoas se dirigem a outras, mesmo a distância.".

Tomar esse processo de constituição de imagem de um interlocutor possibilita observar que, quando isso acontece, os sujeitos recuperam todas as situações de interação que já viveram, buscando imaginar as reações de interlocutores desconhecidos, tentando se antecipar a isso, tomando como ponto de partida as situações de interlocução passadas.

Assim, tais constatações acerca da constituição dos níveis de interlocução do correspondente ao interlocutor real, levam-nos a considerar que esse corresponde à imagem do professor, porque, ao ser ativado no momento da produção do textos, é a sua imagem que media e orienta 0 processo de escrita do candidato, especialmente, por considerarmos que, conforme tratou Bakhtin/Volochinov (1992), o sujeito possui dentro de si um "auditório social" definido, que orienta toda sua escrita, fazendo com que, pensando no seu interlocutor, escreva seguindo determinados parâmetros sociais.

$\mathrm{Na}$ esteira de tais reflexões, a despeito de as teorias afirmarem ser a pessoa presente no momento da escrita que constitua o interlocutor real, há a impossibilidade de esse ser assim compreendido na situação do Concurso Vestibular, a partir de uma concepção do plano prático de realização da prova, uma vez que a imagem do aplicador é uma representação que participa do momento de realização da Prova de Redação. Desse modo, o interlocutor real, em contexto de CV, corresponde a um interlocutor "real-imaginado", recuperado pelo candidato no momento da escrita de seu texto, reconstituindo a imagem de um professor.

Concernente à representação do interlocutor virtual a partir do conceito prático, temos a imagem da Banca de avalição. A essa representação atribuímos a ideia de que, embora se marque, no comando, um interlocutor virtual idealizado, o candidato produz seu texto tendo como horizonte os professores que constituem a banca de avalição das redações, uma vez que, de fato, são eles quem realizam a avaliação dos textos produzidos pelos candidatos e atribuem conceitos que implicam na aprovação ou não do candidato na Prova de Redação.

Ainda assim, temos a compreensão de que a representação do interlocutor virtual na situação de Concurso Vestibular, mesmo no plano prático, tem caráter hermético. Se observarmos que a Banca de avaliação segue, para a avaliar os textos dos candidatos, os parâmetros estabelecidos pela instituição, temos instaurada uma imagem de interlocutor virtual que representa um interlocutor superior, ou seja, há uma representação complexa a partir da qual a banca torna-se um interlocutor 
idealizado que constitui, por sua vez, a imagem da instituição de ensino.

Desse modo, esse processo de representação revela que o interlocutor correspondente à Banca de avalição, ao ser considerada interlocutor virtual, tem função de representação, já que exerce o papel de avaliador dos textos a partir dos parâmetros estabelecidos pelo interlocutor superior, ou seja, a instituição de ensino que dita as regras e os critérios a serem considerados para a avalição das provas.

Tal situação gera reflexões acerca da complexidade da constituição do interlocutor virtual, uma vez que, embora corresponda à Banca de avalição, isto é, o interlocutor que o candidato idealiza como o leitor de seu texto, que avaliará sua produção escrita, na verdade, opera como representação da instituição. Assim, tomando como parâmetro para as discussões do conceito aplicado ao plano prático, considerando o conceito teórico e a situação de enunciação efetiva, teremos uma amálgama que representa a constituição da situação interlocutiva instaurada pela Prova de Redação.

Desse modo, constatamos as seguintes constituições: o Aplicador da prova, que tem sua imagem definida como interlocutor real pelo conceito teórico por estar presente no momento da escrita, exerce a função de representação da Banca de avaliação dos textos produzidos; no plano prático, o aplicador da prova, não tem sua imagem ligada ao momento de produzir o texto por parte dos candidatos, uma vez que estes recuperam a imagem de um professor a quem, no passado, realizaram alguma atividade de escrita e faz parte do seu repertório de práticas de produção textual ao longo de sua trajetória.

O Editor da revista, interlocutor virtual a partir do conceito teórico, marcado linguisticamente no comando, constitui essa posição em um plano idealizado, ao passo que, com base no conceito prático, o interlocutor virtual refere-se à Banca de avaliação, que tem sua imagem definida como o leitor real do texto que está sendo produzido. Ainda assim, a Banca de avalição, ainda que inferida pela situação do CV, exerce função de representação, ao avaliar textos representando os parâmetros definidos pela instituição, uma vez que esse caráter de delimitação de parâmetros definem a instituição como o interlocutor superior em ambas as conceituações (teórica e prática).

Nesse sentido, a despeito de apresentar um interlocutor real-físico, um interlocutor realrecuperado, de se marcar um interlocutor virtual idealizado no Encaminhamento de produção ou de poder inferi-lo e, ainda, de se estabelecer um interlocutor superior devido à própria situação enunciativa, o candidato ainda produz o texto para o interlocutor real.

\section{As condições de produção: ter o porquê, para quem, o que e como dizer}

Considerar o processo de produção dos textos, conforme propõem Fiad e Mayrink-Sabinson (1991), implica em observar suas etapas de produção. Para Geraldi (1997), corresponde ao fato de que para que um sujeito produza textos, seja de gêneros orais ou escritos, é preciso que haja a disponibilização de condições para ter o porquê dizer, ou seja, uma finalidade para dizer o que irá dizer em seu texto e, por consequência, um interlocutor que caracteriza o para quem dizer o que será dito, um conteúdo temático, correspondendo ao o que dizer e um gênero discursivo, previamente delimitado, dando condições de realizar sua produção textual tendo um direcionamento para o como escrever.

Desse modo, como na situação de Concurso Vestibular há a impossibilidade de realização das etapas de planejamento, execução, revisão e reescrita dos textos, característica de uma situação de escrita que considera a interação como inerente a todas as relações, sob orientação de um professor, conforme acontece nas produções textuais em contexto de ensino e aprendizagem, partimos da análise das condições de produção (MENEGASSI, 2011; COSTA-HÜBES, 2012) disponibilizadas pelos encaminhamentos de produção textual da Prova de Redação da Unespar, uma vez que são o parâmetro 
para avaliarmos ${ }^{4}$ a partir de quais condições os candidatos desenvolveram a escrita de seus textos.

Quanto às etapas de produção dos textos, é importante ressaltar que, ainda que não orientadas, 0 candidato tem condições de planejar, escrever, revisar e reescrever seu texto, desde que tenha conhecimento dessa prática e saiba, por exemplo, como melhor utilizar a folha de rascunho disponibilizada. Acreditamos que, em certa medida, o fato de o Concurso disponibilizar a folha de rascunho pode contribuir significantemente para que os candidatos atendam ao solicitado pelas propostas de produção, pois, com ela, há condições de produzir uma versão primeira de seu texto, podendo revisá-la observando possíveis adequações e modificações, objetivando produzir um texto adequado ao solicitado pela Prova de Redação.

$$
\text { Conforme Luz e Beloti (2018), os }
$$
encaminhamentos de produção textual dos anos de 2016/2016, 2016/2017 e 2017/2018 estabelecem todas as condições de produção necessárias para que os candidatos produzam seus textos, atendendo, desse modo, ao proposto pelas teorias norteadoras do processo de escrita. Assim, o comando de produção marca a finalidade, os interlocutores, o gênero, o suporte, a circulação e o posicionamento social do qual o produtor deve escrever, além de, em algumas propostas, serem apresentadas estratégias para a escrita, no todo do encaminhamento de produção textual.

Ao estabelecer todas as condições de produção, os encaminhamentos de escrita dão aos candidatos possibilidades de desempenharem atuação adequada, atendendo, então, à proposta de produção textual do Concurso Vestibular.

\section{Atuação de candidatos no Concurso Vestibular da Unespar}

A atuação dos candidatos investigada nesta pesquisa corresponde a três Concursos Vestibular da Unespar, considerando as 126 produções realizadas pelos candidatos ao curso de Letras do campus de Campo Mourão, nas três edições. As análises baseiam-se nos seguintes dados: na edição de 2016/2016, 31 candidatos realizaram a Prova de Redação, cujo tema solicitado foi "a importância da leitura para o exercício da cidadania”, a ser abordado a partir do gênero Resposta InterpretativoArgumentativa.

Já na edição 2016/2017, 61 candidatos realizaram a Prova de Redação que propôs a temática "o excesso de imagens que não amplia a visão de mundo", solicitando que se posicionassem por meio do gênero Carta do Leitor. Na última edição, 2017/2018, 34 candidatos produziram textos na Prova de Redação, posicionando-se quanto à "importância de sermos éticos em nossas ações cotidianas para construirmos uma sociedade mais próspera e justa", no gênero Artigo de Opinião. A partir dessas informações e da análise dos textos produzidos, apresentamos no Quadro 2 os resultados a que chegamos como base nas investigações que propusemos:

Quadro 2 - Atuação dos candidatos dos Concursos Vestibular de 2016/2016, 2016/2017 e 2017/2018

\begin{tabular}{|c|c|c|c|c|c|c|c|c|}
\hline \multirow{2}{*}{ Edição } & \multirow{2}{*}{$\begin{array}{c}\text { Total de } \\
\text { produções }\end{array}$} & \multicolumn{2}{|c|}{ Organização composicional } & \multicolumn{3}{|c|}{ Conteúdo temático } & \multirow{2}{*}{$\begin{array}{c}\text { Outros } \\
\text { gêneros }\end{array}$} \\
\cline { 3 - 9 } & & Atende & $\begin{array}{c}\text { Atende } \\
\text { parcialmente }\end{array}$ & $\begin{array}{c}\text { Não } \\
\text { atende }\end{array}$ & Atende & $\begin{array}{c}\text { Atende } \\
\text { parcialmente }\end{array}$ & $\begin{array}{c}\text { Não } \\
\text { atende }\end{array}$ & 5 \\
\hline $2016 / 16$ & 31 & 2 & 9 & 15 & 5 & 21 & 5 & 11 \\
\hline $2016 / 17$ & 61 & 11 & 19 & 20 & 19 & 21 & 21 & 7 \\
\hline $2017 / 18$ & 34 & 9 & 10 & 6 & 13 & 14 & $\mathbf{3 3}$ & $\mathbf{2 5}$ \\
\hline Total & $\mathbf{1 2 6}$ & $\mathbf{2 2}$ & $\mathbf{3 8}$ & $\mathbf{4 1}$ & $\mathbf{3 7}$ & $\mathbf{5 6}$ & $\mathbf{3 3}$ \\
\hline
\end{tabular}

Fonte: Os pesquisadores.

\footnotetext{
4 As análises dos textos dos candidatos se dão a partir de critérios estabelecidos pelos pesquisadores e não têm relação com os critérios utilizados pela Banca de avalição dos textos. Esses critérios podem ser consultados, detalhadamente, em Autor B e Autor A (2018a).
}

\footnotetext{
${ }^{5}$ Os números referentes à produção de outros gêneros textuais não são contabilizados quanto aos critérios estabelecidos para esta pesquisa, uma vez que não pertencem aos gêneros solicitados.
} 
As análises dos textos produzidos pelos candidatos revelaram que, além de alguns resultados, como o atendimento, o atendimento parcial e o não atendimento, tanto no que diz respeito à organização composicional dos gêneros solicitados, quanto ao conteúdo temático, devido a diversos fatores, os candidatos ainda produziram gêneros outros que não os solicitados marcadamente no comando de produção da Prova.

Tais resultados chamam-nos a atenção e levam-nos a refletir de modo mais sistemático cada um dos fatos que implicam no atendimento parcial e no não atendimento, uma vez que os casos de atendimento encaixam-se no esperado pela Prova. Possibilitam, também, avaliar a respeito dos possíveis motivos que levam os candidatos a produzirem outros gêneros textuais, uma vez que, a partir da análise dos encaminhamentos da Prova, verificamos que as condições de produção, necessárias para que os candidatos escrevessem seus textos adequados à situação de enunciação estabelecida, são proporcionadas, isto é, a proposta estabelece finalidades, interlocutores, gênero, suporte, circulação e posicionamento social para a constituição da situação.

A fim de elucidar e discutir as ocorrências quanto à atuação dos candidatos nos aspectos: a) organização composicional dos textos; b) conteúdo temático; c) produção de outros gêneros; discutimos, na sequência, a respeito do quantitativo correspondente a cada um desses aspectos.

$\mathrm{Na}$ edição de 2016/2016 do Concurso Vestibular, apenas 2 candidatos atenderam à organização composicional do gênero Resposta Interpretativo-Argumentativa, de modo que 9 atenderam parcialmente e 15 não atenderam. A leitura dos textos permitiu-nos identificar que, aos números referentes ao atendimento parcial e não atendimento estão atreladas as ocorrências de: fragilidade argumentativa nos textos - os 9 candidatos que atenderam parcialmente; textos sem marca de resposta - 10 dos 15 candidatos que não atenderam; textos com títulos - 4 candidatos; texto com título e sem resposta -1 candidato.
$\mathrm{Na}$ edição de 2016/2017, 11 candidatos atenderam à organização composicional do texto, 19 apenas parcialmente e 20 não atenderam. Quanto à atuação dos 19 que atenderam parcialmente, 4 é devido à ausência de marcas típicas do gênero e à marcação do interlocutor errado; 1 por marcar o interlocutor errado, não apresentar as marcas típicas do gênero e demonstrar fragilidade argumentativa; enquanto 14 apresentam a ausência das marcas típicas do gênero e fragilidade argumentativa em seus textos. Já, dos 20 candidatos que não atenderam, 7 não respondem ao texto solicitado; 9 não marcam o interlocutor; 4 apresentam título.

No Concurso Vestibular de 2017/2018, do total de 34 candidatos que realizaram a Prova de Redação, 9 atenderam, 10 atenderam parcialmente e 6 não atenderam à organização composicional do gênero, de modo que os 10 candidatos que atenderam parcialmente têm esse resultado ligado ao fato de produzirem textos com fragilidade argumentativa. Quanto aos 6 que não atenderam, 1 candidato assina seu texto ao fim da produção; 1 não escreve o mínimo de linhas; 4 não apresentam posicionamento diante do tema.

Observando os dados referentes aos 3 Concursos Vestibular, verificamos que na edição de 2016/2016 o número de não atendimento é maior que o de atendimento e atendimento parcial. Já na edição 2016/2017, mantém-se o desempenho do não atendimento como maior ocorrência, contudo, nessa ocasião, a quantidade de provas com atendimento parcial é bastante próxima ao total de provas com não atendimento, de modo que se observa, ainda, aumento significativo no número de atendimento. $\mathrm{Na}$ edição de 2017/2018, detectamos que o número de não atendimento cai, sobe o de atendimento e, com maior recorrência, nessa edição, destaca-se o de atendimento parcial.

De maneira geral, os números revelam que, embora os não atendimentos sejam maiores, as situações de atendimento parcial são bastante próximas. Por meio de tais dados, constatamos que há algumas recorrências nos fatores que implicam no atendimento parcial e não atendimento às condições 
de produção: a fragilidade argumentativa e a ausência de marcas típicas dos gêneros. Refletindo acerca dessas ocorrências, acreditamos que, possivelmente, os candidatos demonstram não reconhecer a estrutura dos gêneros solicitados e, ainda, apresentam limitações ao posicionar-se com argumentos, considerando o fato de os gêneros textuais solicitados pertencerem à ordem do argumentar.

Nesse sentido, um aspecto é passível de reflexão: o fato de não conhecer a estrutura composicional do gênero poderia ter seu impacto na avaliação da prova reduzido, caso 0 aspecto argumentativo fosse adequado à proposta. Portanto, considerando o caráter discursivo de adequação à situação de enunciação, para que se atenda à composição organizacional do gênero, é fundamental o posicionamento com argumentos, pois esse é um fator determinante para a adequação do texto produzido. Escrever textos com pouco ou sem argumentos demonstra não apenas uma possível dificuldade com a escrita, mas, também, um fator relacionado às práticas de leitura, que constituem os conhecimentos de mundo e a memória discursiva desses sujeitos, produtores destes textos, cuja enunciação demanda domínio argumentativo.

Contudo, se partirmos do pressuposto de que, majoritariamente, a produção textual acontece nas aulas de Língua Portuguesa nas escolas podemos compreender que, além de um amplo quadro de questões subjetivas que implicam na situação de produção de textos em Concursos, como, por exemplo, a tensão que é própria da situação avaliativa, esses resultados podem estar ligados ao ensino de Língua Portuguesa que é desenvolvido nas escolas, especialmente, às práticas de escrita que são desenvolvidas pelos candidatos, quando estudantes.

$\mathrm{Na}$ esteira da síntese de tais registros e análises, dois aspectos sobressaem-se: a escrita e a leitura. Nesse sentido, analisar a atuação de candidatos, tomados como sujeitos produtores de textos, em determinadas situações de enunciação marcadas, não basta refletirmos a respeito da constituição de sua prática de escrita, mas é válido o destaque de que a prática de leitura, especialmente, nestas situações que demandam domínio argumentativo pelo vínculo dos gêneros solicitados à ordem do argumentar, também deve ser analisada e tomada como parâmetro de reflexão.

No que se refere ao conteúdo temático solicitado para a produção dos textos, em 2016/2016, 5 candidatos atenderam, 21 parcialmente, enquanto 5 não atenderam. Dos 21 candidatos que antederam parcialmente, 15 são devido à inadequação de linguagem; 3 à fragilidade argumentativa; 3 a ambos os fatores. Já os 5 candidatos que não atenderam têm esse resultado atribuído ao fato de 4 fugirem ao tema; 1 apresentar cópias de trechos dos textos de apoio.

Chamamos atenção, aqui, para a fragilidade argumentativa como fator de atendimento parcial ao conteúdo temático do texto. Esse pode ser assim considerado, uma vez que, para atender ao conteúdo solicitado para a produção do texto, o candidato deverá posicionar-se com argumentos para, além de defender sua posição, apresentar informações sobre o que está sendo dito. Nesse sentido, a fragilidade argumentativa está indissociavelmente ligada ao texto que se produz, não só como constitutiva da organização composicional do texto, mas também do conteúdo temático, já que a organização composicional, o conteúdo temático e o estilo de linguagem engendram ao gênero discursivo como unidade constituinte de sua essência (BAKHTIN, 2003).

$\mathrm{Na}$ edição de 2016/2017, do total de 61 candidatos, 19 atenderam, 21 atenderam parcialmente e 21 não atenderam ao conteúdo temático solicitado. Dos 21 candidatos que atenderam parcialmente, 16 deve-se à fragilidade argumentativa; 5 à inadequação do estilo de linguagem. Quanto aos 21 que não atenderam, 16 fugiram ao tema proposto; 5 apresentaram cópias de trechos dos textos de apoio.

Já na edição de 2017/2018, 13 candidatos atenderam, 14 atenderam parcialmente e 7 não atenderam. Entre os 14 atendimentos parciais, 7 são 
devido à fragilidade argumentativa apresentada nos textos; 4 à inadequação de linguagem; 3 a ambos os fatores. Os 7 que não atenderam têm esse resultado ligado ao fato de os candidatos fugirem ao tema solicitado.

Com esses registros de pesquisa é possível identificar que na edição de 2016/2016 os números quanto ao atendimento parcial são maiores e, embora os referentes ao atendimento e não atendimento sejam iguais, esses são baixos. $\mathrm{Na}$ edição de 2016/2017, os números ficam bastante próximos, sobressaindo, ainda, os de atendimento parcial, que nessa edição é o mesmo que os de não atendimento. Já em 2017/2018, os números referentes ao atendimento parcial são, mais uma vez, maiores, estando muito próximo aos números de atendimento, de modo que detectamos uma baixa significativa nos números de não atendimento.

Esses dados chamam-nos atenção e levamnos a refletir a respeito da interferência do encaminhamento de produção textual ao marcar o conteúdo temático solicitado para a produção do candidato e, também, apresentar textos de apoio para dar condições de o candidato ter o que dizer. $O$ ter o que dizer é, conforme afirma Geraldi (1997), um aspecto que deve ser considerado em toda situação de produção de textos. Na enunciação constituída no Concurso Vestibular, devido ao fato de, em alguns contextos, o tema ser desconhecido pelo candidato, os textos de apoio cumprem o papel de contribuir para o direcionamento temático da prova, dando condições de o candidato, minimamente, conhecer a respeito do tema e, ainda, se possível, posicionar-se em sua prova.

Antunes (2003) afirma que "Ter o que dizer é [...] uma condição prévia para o êxito da atividade de escrever. Não há conhecimento linguístico (lexical ou gramatical) que supra a deficiência do "não ter o que dizer'." (p. 45, grifos da autora). Nesse sentido, compreendemos que o fato de os números de atendimentos parciais serem maiores nas três edições do CV e, em 2016/2017 e 2017/2018, os atendimentos estarem muito próximo dos atendimentos parciais, podem ser indícios de que a
Prova de Redação da Unespar possibilitou aos candidatos refletirem sobre o conteúdo temático, organizando as informações e argumentos que apresentam em seus textos. Logo, ainda que os candidatos desconhecessem totalmente a proposta de conteúdo temático delineado no comando, os textos que compõem o encaminhamento de produção e o próprio enunciado que introduz o comando de produção cumprem a função de constituir o aspecto $o$ que dizer.

Além dos gêneros solicitados pelos encaminhamentos de produção textual, observamos, ao analisar os textos produzidos pelos candidatos, a ocorrência de produções que não correspondiam ao gênero textual proposto. Acreditamos que esses resultados podem estar, também, atrelados às práticas de produção de textos na disciplina de Língua Portuguesa e nas demais disciplinas nas escolas, uma vez que esse resultado apresenta-se como uma espécie de extensão do que verificamos nas discussões acerca da atuação dos candidatos no que diz respeito à organização composicional dos gêneros, quando grande parte dos candidatos revela desconhecer as marcas típicas dos gêneros textuais.

$\mathrm{Na}$ edição de 2016/2016, 4 candidatos produziram dissertações, enquanto 1 produziu Carta do Leitor. Em 2016/2017, 11 candidatos produziram dissertação, enquanto 9 também produziram dissertações, em 2017/2018. Embora não pudéssemos avaliar as produções quanto à organização composicional, considerando o fato de não pertencerem ao gênero em foco, em cada Concurso Vestibular, enquanto objeto de estudo desta pesquisa, buscamos identificar, ainda, se estas produções atendem ao conteúdo temático solicitado.

Ao analisarmos tais textos, observamos que, em 2016/2016, o candidato que produziu a Carta do Leitor atende à temática. Quanto aos 4 que produziram dissertações, 2 atendem ao conteúdo temático, enquanto 2 atendem parcialmente devido à fragilidade argumentativa. Na edição de 2016/2017, dos 11 candidatos que produziram dissertações, 2 atendem à temática e 9 atendem parcialmente devido à fragilidade argumentativa. Já na edição de 
2017/2018, dos 9 candidatos que produziram textos correspondentes à dissertação, 7 atendem à temática e 2 não atendem, pois fogem ao tema.

Desse modo, é possível observar que, embora os candidatos produzam gêneros diferentes dos solicitados pela Prova de Redação do Concurso Vestibular da Unespar, estes, ao partirem da interpretação dos textos de apoio, têm condições de atendimento total, ou mesmo parcial, do conteúdo temático da produção textual. Revelando, desse modo, que a instituição possibilita, por meio do encaminhamento de produção textual, aos candidatos terem o que dizer (GERALDI, 1997).

O ter o que dizer, nesse contexto, assume uma face da produção textual como processo, ou seja, dotada do caráter discursivo, insere o candidato nos planos de "[...] conteúdo a dizer e razões ou motivações para dizer." (GERALDI, 1997, p. 139), ao passo que o candidato argumenta, assumindo posicionamento, com argumentos para defender sua posição, constituindo, assim, o aspecto caracterizado como "de onde se fala".

\section{Considerações finais}

As análises apresentadas neste trabalho revelam que, embora os encaminhamentos de produção textual estejam adequados à perspectiva discursiva de linguagem (BAKHTIN/VOLOCHINOV, 1992), estabelecendo todas as condições necessárias para a produção de textos inseridos em determinada situação enunciativa (MENEGASSI, 2011; COSTAHÜBES, 2012), os candidatos demonstram não ter conhecimento da prática de escrita como trabalho (FIAD; MAYRINK-SABINSON, 1991), não produzindo textos que consideram as condições que the são disponibilizadas e, assim, que não atendem adequadamente à situação de enunciação estabelecida.

Esse desconhecimento acerca da prática de escrita como trabalho implica na incompreensão, também, dos diferentes gêneros de texto que circulam socialmente e suas respectivas funções sociais e comunicativas. Considerando o fato de essas práticas acontecerem nas escolas, na maioria das vezes, na disciplina de Língua Portuguesa, ao identificarmos que os candidatos não as reconhecem, atribuímos a este resultado a possibilidade de ser um reflexo de práticas de escrita nas escolas, não correspondendo ao preconizado pela teoria relativa ao conceito de escrita como trabalho (FIAD; MAYRINK-SABINSON, 1991).

Essas observações têm relação com a proposta de escrita como trabalho, uma vez que é considerado por essa vertente ser necessário estabelecer condições delineadoras da escrita de textos com gêneros definidos e que, a partir dessas condições o produtor assuma autoria do texto, atendendo à organização do gênero discursivo solicitado, ao conteúdo temático, considerando que são disponibilizados textos de apoio para auxiliá-lo no ter o que dizer, bem como na delimitação da sua posição, enquanto autor que defende seu ponto de vista, atuando como sujeito social por meio da escrita, em estilo de linguagem adequado ao seu interlocutor.

Foi possível observar também que, ainda que os números quanto à organização composicional dos textos fossem maior no diz respeito ao não atendimento, na edição de 2017/2018, os números revelam que há um aumento nos pontos positivos. $\mathrm{O}$ mesmo acontece com o conteúdo temático que, embora tenha tido números positivos nas três edições dos Concurso Vestibular, na edição de 2017/2018 o número de atendimento aumentou.

Esse resultado pode revelar que a instituição tem buscado dar condições para os candidatos produzirem seus textos, objetivando um melhor desempenho na prova, uma vez que os resultados expostos aqui podem estar atrelados às práticas de produção de textos nas escolas que, em muitos casos, não prepara, adequadamente, conforme propõem os PCN (BRASIL, 1998), os candidatos para situações como a do Concurso Vestibular, considerando o fato de que essa situação engendra uma das circunstâncias para as quais a escola prepara os estudantes para atuarem socialmente. 


\section{Referências Bibliográficas}

ANTUNES, I. Aula de português: encontro e interação. 1. ed. São Paulo: Parábola Editorial, 2003.

BAKHTIN, M. Estética da criação verbal. 4.e.d. São Paulo: Martins Fontes, 2003.

BAKHTIN, M./ VOLOCHINOV, V. N. Marxismo e filosofia da linguagem. 6. ed. São Paulo: Hucitec, 1992.

BELOTI, A. A formação teórica, metodológica e prática dos conceitos de revisão e reescrita no PIBID de língua portuguesa. 2016. 227 f. Tese (Doutorado) - Programa de Pós-Graduação em Letras, Universidade Estadual de Maringá, Maringá, 2016.

BRASIL. Secretaria de Educação Fundamental. Parâmetros Curriculares Nacionais: Língua Portuguesa, área de linguagens, códigos e suas tecnologias. Brasília: MEC/ SEF. 1998.

BRITTO, L. P. L. Em terra de surdos-mudos (um estudo sobre as condições de produção de textos escolares). In: GERALDI, João Wanderley. (Org.). O texto na sala de aula. 4. ed. São Paulo: Ática, 2006.p. 117-126.

COSTA-HÜBES, T. C. Reflexões sobre os encaminhamentos de produção textual: enunciados em diálogo com outros enunciados. In: Encontro do CELSUL - Círculo de Estudos Linguísticos do Sul, 10., 2012, Cascavel. Anais... Cascavel: UNIOESTE, 2012, p. 1-15.

FARACO, C. A. A produção textual de um estudante ao final do ensino médio. Texto apresentado no Encontro de supervisores de Avaliação de Redações, promovido pela DAEB/INEP. Brasília, 30/08/2014.

FIAD, R. S.; MAYRINK-SABINSON, M. L. T. A escrita como trabalho. In: MARTINS, M. H. (Org.). Questões de linguagem. 4. ed. São Paulo: Contexto, 1991. p. 54-63.

GERALDI, J. W. Portos de passagem. 4.ed. São Paulo: Martins Fontes, 1997.
LUZ, C. S.; BELOTI, A. As condições de produção na prova de redação do concurso vestibular da UNESPAR. Miguilim - Revista Eletrônica do Netlli, Crato, v. 7, n. 1, p.114-132, jan.-abr. 2018.

Provas de redação do Concurso Vestibular da UNESPAR: condições de produção e atuação dos candidatos. In: IV Encontro Anual de Iniciação cientifica da Unespar - EAIC, vol. 4, 2018. Anais ... Paranaguá: UNESPAR, 2018a, 818-843.

MENEGASSI, R. J. Conceitos bakhtinianos na prova de redação. In: Línguas \& Letras/ Universidade Estadual do Oeste do Paraná. Campus de Cascavel. Centro de Educação, Comunicação e Artes. v.1, n.1 (2000). Cascavel: EDUNIOESTE, 2011.p. 99-119.

A escrita como trabalho em sala de aula. In: JORDÃO, C. M. (Org.). A linguística aplicada no Brasil: rumos e passagens. Campinas, SP: Pontes Editores, 2016, p. 193-230.

Aspectos sobre o gênero discursivo. In: ANTONIO, J. D.; NAVARRO, P. (Orgs.). Gêneros textuais em contexto de vestibular. Maringá: Eduem, 2017, p. 17-41

SILVA, C. C. Caracterização dos Comandos de produção textual da prova de redação da UEM. 2018. (Dissertação) - Programa de PósGraduação em Letras, Universidade Estadual de Maringá, Maringá, 2018.

SOBRAL, A; GIACOMELLI, K. Observações didáticas sobre a análise dialógica do discurso - ADD. Domínios de Linguagem. Uberlândia. vol. 10, n. 3. pp. 1076-1094. jul/set. 2016.

UNIVERSIDADE ESTADUAL DO PARNÁ. Comissão Central do Concurso Vestibular. Manual do Candidato. Unespar, 2017. Disponível em: $<$ http://vestibular.unespar.edu.br/arquivosvestibular-2017/manual-vestibular-da-unesparsite>. Acesso em: 02 jan. 2019.

\section{COMO CITAR ESSE ARTIGO}

BELOTI, Adriana; LUZ, Cleber da Silva. Práticas de escrita em contexto de Concurso Vestibular: a atuação de candidatos na prova de Redação. Signo, Santa Cruz do Sul, v. 44, n. 80, ago. 2019. ISSN $1982-2014$. Disponível em: <https://online.unisc.br/seer/index.php/signo/article/view/13244>. Acesso em: doi: https://doi.org/10.17058/signo.v44i80.13244. 